\title{
Epithelial mesenchymal transition status is associated with anti-cancer responses towards receptor tyrosine-kinase inhibition by dovitinib in human bladder cancer cells
}

Jörg Hänze ${ }^{*}$, Marcus Henrici ${ }^{\dagger}$, Axel Hegele, Rainer Hofmann and Peter J Olbert

\begin{abstract}
Background: Dovitinib (TKI-258) is a receptor tyrosine kinase (RTK) inhibitor targeting fibroblast growth factor receptor (FGFR) and further related RTKs. TKI-258 is under investigation as anticancer drug for the treatment of various cancers including bladder cancer with aberrant RTK signaling. Here, we analyzed the responses of ten human bladder cancer cell lines towards TKI-258 treatment in relation to the epithelial mesenchymal transition (EMT) status of the cells.
\end{abstract}

Methods: Expression of epithelial marker E-cadherin as well as mesenchymal markers $\mathrm{N}$-cadherin and vimentin was determined by quantitative RT-PCR and Western-blot in RNA and protein extracts from the cultured cell lines. The cell responses were analyzed upon addition of TKI-258 by viability/proliferation (XTT assay) and colony formation assay for measurement of cell contact independent growth.

Results: The investigated bladder cancer cell lines turned out to display quite different EMT patterns as indicated by the abundance of E-cadherin or N-cadherin and vimentin. Protein and mRNA levels of the respective components strongly correlated. Based on E-cadherin and N-cadherin mRNA levels that were expressed approximately mutual exclusively, an EMT-score was calculated for each cell line. A high EMT-score indicated mesenchymal-like cells and a Iow EMT-score epithelial-like cells. Then, we determined the $\mathrm{IC}_{50}$ values for TKI-258 by dose response curves (0-12 $\mu \mathrm{M}$ TKI-258) in XTT assays for each cell line. Also, we measured the clonogenic survival fraction after adding TKI-258 $(1 \mu \mathrm{M})$ by colony formation assay. We observed significant correlations between EMT-score and IC $C_{50}$ values $(r=0.637$, $p=0.0474)$ and between EMT-score and clonogenic survival fraction $(r=0.635, p=0.0483)$ as analyzed by linear regression analyses.

Conclusions: In sum, we demonstrated that the EMT status based on E-cadherin and N-cadherin mRNA levels may be useful to predict responses towards TKI-258 treatment in bladder cancer.

Keywords: Receptor tyrosine kinase, Tyrosine kinase inhibition, Bladder cancer, Epithelial mesenchymal transition

\footnotetext{
* Correspondence: joerg.haenze@med.uni-marburg.de

${ }^{\dagger}$ Equal contributors

Department of Urology and Pediatric Urology, Philipps University of Marburg,

Baldingerstraße, 35043 Marburg, Germany
} 


\section{Background}

Receptor tyrosine kinase (RTK) signaling is altered in urothelial cancer. Namely, FGFR dependent signaling is affected [1]. FGFR3 mutations causing ligand independent dimerization and enhanced kinase activity with constitutive FGFR3 activation are prevalent in low grade non muscle invasive transitional cell carcinoma (TCC) whereas overexpression of wild type FGFR3 is observed in muscle invasive bladder cancer [2-4]. Also, aberrant expression of FGFR1, FGFR2, and FGF2 ligand has been demonstrated [5-7]. Further RTKs such as VEGFR and PDGFR are involved in bladder cancer progression [8]. Therefore, drugs for inhibition of RTKs are under investigation for the treatment of bladder cancer. Among those, TKI-258 targeting signaling of FGFR/PDGFR/VEGFR and further related RTKs is investigated as a potential anti TCC compound $[9,10]$. The affinity order for TKI-258 has been determined for different RTKs being highest for FGFR1 and FGFR3 followed by VEGFR1-3, PDGFR $\beta$, FLT-3 and c-Kit revealing the complexity of the drug [11]. The responsiveness towards RTK inhibitors is difficult to predict in bladder cancer $[7,10]$. Patients with non muscle invasive bladder cancer have a good outcome and only a small portion of these tumors progress to metastatic disease. Muscle-invasive TCC is more prone to become metastatic and oncological outcome is much poorer. An indicator of metastatic potential is the EMT status [12]. EMT is associated with enhanced cell migration and metastasis revealing a more aggressive cancer type. Bladder cancer cells can strongly differ in epithelial and mesenchymal characteristics as revealed by different cadherin subtype expression patterns $[13,14]$. Cadherins are transmembrane cell adhesion proteins that are important during development and play a role in various diseases including cancer. Ecadherin is expressed in epithelial cells. E-cadherin has characteristics of a tumor suppressor that inhibits cell invasion and loss of E-cadherin is important for induction of EMT [15]. During EMT a cadherin switch occurs. Ecadherin is replaced by N-cadherin a well established mesenchymal cell type marker in pathology [14]. P-cadherin is a further cadherin subtype expressed in malignancies but could not yet been assigned to an epithelial or mesenchymal cell type in bladder cancer $[14,16]$. The mesenchymal marker vimentin represents an intermediate filament that replaces the epithelial cytokeratin filament [17]. The cadherin switch involves transcriptional regulation by epithelial repressors (e.g. snail) for downregulation of E-cadherin and mesenchymal activators (e.g. $\beta$-catenin) for upregulation of N-cadherin [18].

Interestingly, unsupervised gene cluster analysis by global gene expression profiling has demonstrated that nonmuscle invasive and muscle invasive TCC fall into two distinct subgroups that identified EMT-related genes as relevant [19-21]. The meaning of EMT status for drug responses towards inhibition of epidermal growth factor receptor has been reported in bladder cancer cells and revealed a relevance of E-cadherin expression [22,23].

Here, we characterized ten human bladder cancer cell lines with respect to expression of E-cadherin, $\mathrm{N}$-cadherin and vimentin. Furthermore, we analyzed the response of these cells towards treatment with TKI-258 by proliferation/viability assay and colony formation assay. We observed that cells with epithelial characteristic had a stronger therapeutically beneficial response to TKI-258 than cells with mesenchymal characteristics. Thus, analysis of the EMT status may help to predict TKI-258 responsiveness independent of molecular analysis of RTK signaling.

\section{Methods}

\section{Cell culture}

Human bladder cancer cell lines T24, HT1376, BFTC905, 5637, HU456, UMUC3, RT4, RT112, TCC-SUP, MGHU4 were cultured in RPMI1640 medium supplemented with $10 \%$ fetal bovine serum, $1 \%$ stable glutamine and $1 \%$ Penicillin/Streptomycin solutions (PAA Laboratories, Pasching, Austria) at $37^{\circ} \mathrm{C}$ with $5 \% \mathrm{CO}_{2}$ in humidified air. Dovitinib (TKI-258) was kindly provided by Novartis Pharma AG (Basel, Switzerland). RT4 and RT112 cells are known to be wild type for FGFR3 and T24 and UMUC3 have activating RAS mutations acting downstream of RTKs [10].

\section{RNA and protein extraction}

RNA and protein extraction was performed with Trifast (Peqlab, Erlangen, Germany) according to the manufacturer's protocol.

\section{Quantitative real time RT-PCR}

$1 \mu \mathrm{g}$ RNA was used as template for cDNA synthesis after digest of genomic DNA with RNase-free DNase (RevertAid First Strand cDNA synthesis Kit, Fermentas Life Science, St. Leon-Rot, Germany). Realtime RT-PCR was performed with SYBR Green Fluorescein Mix (ABgene UK, Epsom, UK). Cycling conditions were, $95^{\circ} \mathrm{C}$ for $15 \mathrm{~min}$, followed by 45 cycles of $95^{\circ} \mathrm{C}$ for $15 \mathrm{~s}, 60^{\circ} \mathrm{C}$ for $15 \mathrm{~s}, 72^{\circ} \mathrm{C}$ for $30 \mathrm{~s}$. Relative levels of mRNA are displayed as $-\Delta \mathrm{Ct}$ values with the mean of $\beta$-actin and porphobilinogen deaminase (PBGD) as reference mRNA $\left(\Delta \mathrm{Ct}=\mathrm{Ct}_{\text {target } \mathrm{mRNA}}-\mathrm{Ct}_{\text {reference } \mathrm{mRNA}}\right)$. The following primer sets (+, forward; -, reverse) were employed: N-cadherin (+: CAA TCC TCC AGA GTT TAC TGC CAT G, -: GAT TGG TTT GAC CAC GGT GAC TAA C), E-cadherin (+: TGA AAA GAG AGT GGA AGT GTC CGA G, -: GAT TAG GGC TGT GTA CGT GCT GTT C), P-cadherin (+: GAC ACC TTC CGA GGG AGT GTC TTA G, -: GGA TGG TCA GTG TGT ACT CAG GGA C), Vimentin (+: GCA AAG CAG GAG TCC ACT GAG TAC C, - TGT CAA GGG CCA TCT TAA 
CAT TGA G), PBGD (+: TGT CTG GTA ACG GCA ATG CG, -: CCC ACG CGA ATC ACT CTC AT), FGFR3 (+: GAA AGA CGA TGC CAC TGA CAA GGA C, -: TCC TTG AAG GTG AGC TGC TCC TC), $\beta-$ actin (+: TAT CCA GGC TGT GCT ATC CCT GTA C, -: TTC ATG AGG TAG TCA GTC AGG TCC C) (Biomers $\mathrm{GmbH}$, Ulm, Germany). The EMT-score was defined as (- $\Delta$ ct $\mathrm{N}$-cadherin) $-(-\Delta$ ct E-cadherin).

\section{Western blot}

After determination of protein concentration (Pierce BCA Protein Assay, Thermo Scientific, Rockford, USA), $40 \mu \mathrm{g}$ of each sample was subjected to sodium dodecyl sulphate polyacrylamide gel electrophoresis ( $10 \%$ polyacrylamide) and transferred to polyvinylidene fluoride membrane (Millipore, Bedford, USA) by electrophoresis. The membranes were blocked at room temperature for $1.5 \mathrm{~h}$. Primary antibodies for vimentin (dilution 1:2500), E-cadherin (dilution 1:5000), N-cadherin, (dilution 1:2000) (all of these polyclonal rabbit antibodies (Abgent, San Diego, USA) and for $\beta$-actin (dilution 1:5000; monoclonal mouse Abcam, Cambridge, UK) were added and incubated overnight at $4{ }^{\circ} \mathrm{C}$ in trisbuffered saline with $0.1 \%$ tween containing $5 \%$ dry milk. Then, secondary horseradish peroxidase coupled antirabbit or anti-mouse immunoglobulin (both dilution 1:2000; Thermo Scientific, Rockford, USA) was added for band detection with enhanced chemiluminescent luciferase kit (Thermo Scientific, Rockford, USA) by an image system (Fluorchem IS-8900, Alpha Innotech, San Leandro, USA) allowing measurement of band intensity for determination of relative protein abundance.

\section{Proliferation/viability assay}

TACS XTT-Kit (Trevigen, Gaithersburg, USA) with a long term protocol was used to assess the effects of TKI-258 on cell viability, an assay that closely correlates with proliferation. Cells were seeded into 96-well plates with $150 \mu \mathrm{l}$ medium and TKI-258 was added one day later in a dose range as indicated $(0.25 \mu \mathrm{M}-12 \mu \mathrm{M})$. Medium and TKI-258 was replaced once after $2 \mathrm{~d}$ and incubation continued for further $3 \mathrm{~d}$. Then, XTT solution was added and the optical density was measured at $490 \mathrm{~nm}$. The $\mathrm{IC}_{50}$ values were calculated by non-linear regression analysis with the equation of a sigmoidal dose response with variable slope (Graphpad Prism 5.0): $\mathrm{Y}=1 /\left[1+10^{\wedge}(\log \mathrm{IC} 50-\mathrm{X})(\right.$ Hillslope $\left.)\right]$.

\section{Colony formation assay}

This assay measures cell proliferation in a cell contact independent way. Cells were plated in pre-tested appropriate densities yielding 100-500 cells per plate. The plates were cultured for 8-12 days in the presence $(1 \mu \mathrm{M})$ or absence $(0 \mu \mathrm{M})$ of TKI-258. Then, the colony signals were densitometrically measured after crystal violet staining. The clonogenic survival fraction was defined as the ratio of signal intensity of untreated group versus TKI-258 $(1 \mu \mathrm{M})$ treated group.

\section{Results}

We analyzed typical components indicating the epithelial or mesenchymal cell status in ten human bladder cancer cell lines. As epithelial marker we measured E-cadherin and as mesenchymal markers $\mathrm{N}$-cadherin and vimentin by Western blot (Figure 1). E-cadherin and N-cadherin

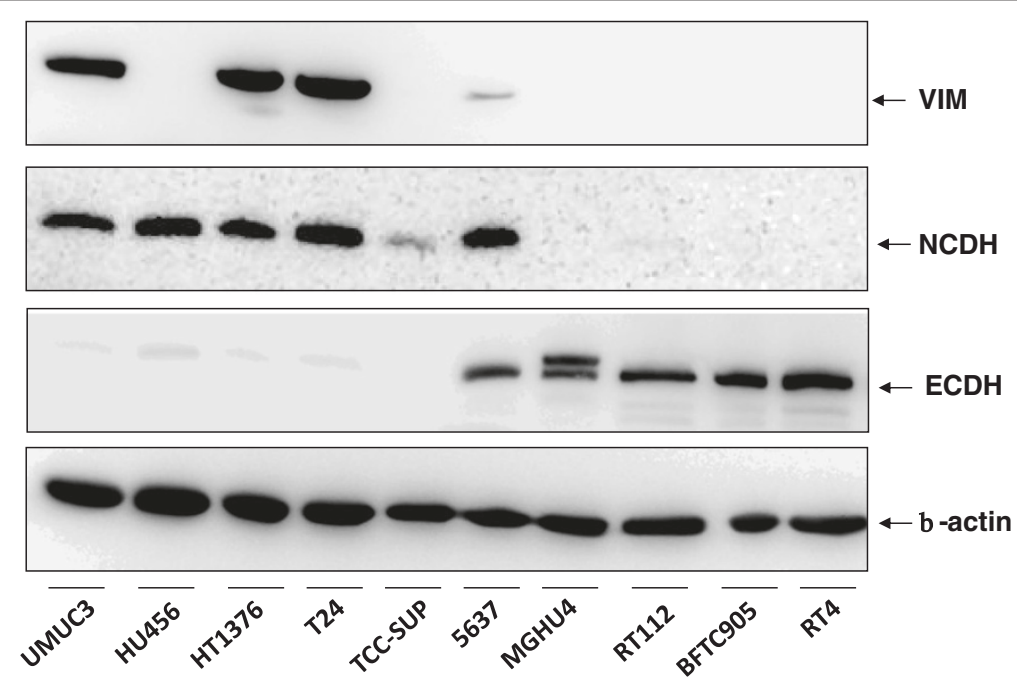

Figure 1 Western-blot analysis of mesenchymal markers vimentin (VIM) and N-cadherin (NCDH) as well as epithelial marker E-cadherin $(E C D H)$ in comparison to cytoplasmic $\beta$-actin in various human bladder cancer cell lines indicated at the bottom. It is obvious that cells strongly differ in the expression levels of VIM, NCDH and ECDH indicating mesenchymal-like or epithelial-like cell characteristics. 


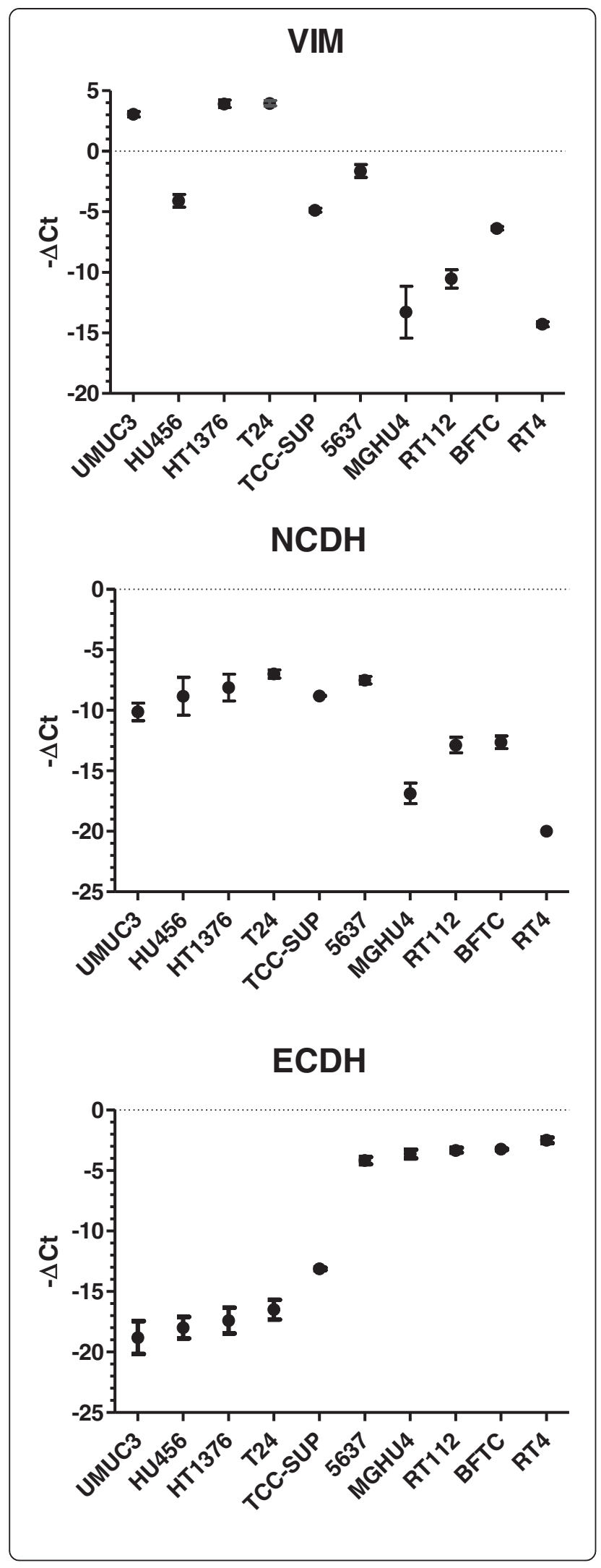

Figure 2 Quantification of mRNA encoding vimentin (VIM), $\mathrm{N}$-cadherin (NCDH) and E-cadherin (ECDH) by realtime RT-PCR in human bladder cancer cell lines. Displayed are the $-\Delta C t$ values ( $C t$, cycle of threshold) normalized to $\beta$-actin and PBGD mRNA (mean, standard deviation, $n \geq 3$ ). The order of cell lines is the same as in the Western-blot and allows direct comparison with Figure 1. Linear regression analysis revealed strong correlation between mRNA and protein levels of $\mathrm{NCDH}, \mathrm{ECDH}$ and VIM, respectively (E-cadherin, $r=0.831, p=0.0029 ; N$-cadherin, $r=0.794, p=0.0061$; vimentin, $r=0.858, p=0.0015$.

expression levels appeared almost mutually exclusive and vimentin was predominantly expressed in those cells that were $\mathrm{N}$-cadherin positive. Next, we quantified the mRNA levels of these components (Figure 2). We revealed strong correlation between mRNA and protein levels suggesting major regulation of these components at the mRNA level.

In addition, we analyzed P-cadherin and FGFR3 (Figure 3). The role of P-cadherin has been ambiguously described in EMT status. FGFR3 was analyzed since FGFR3 was demonstrated to correlate with epithelial markers. Interestingly, we revealed a correlation between P-cadherin and E-cadherin-mRNA levels $(r=0.919, p<0.0001)$ and could confirm the correlation between FGFR3 and E-cadherinmRNA $(\mathrm{r}=0.813, \mathrm{p}<0.0001)$.

Based on the well established and related endpoint markers of EMT status, E-cadherin and N-cadherin, we calculated an EMT-score for each cell line by subtraction of $-\Delta \mathrm{Ct} \mathrm{N}$-cadherin and $-\Delta \mathrm{Ct} \mathrm{E}$-cadherin, respectively (Figure 4). In this term, high values reflect a mesenchymal status and low values an epithelial status. Based on this EMT-score, we analyzed the cell responses towards TKI258 treatment. Employing a proliferation/viability assay, we measured the inhibitory concentration of TKI-258 yielding $50 \%$ viable cells $\left(\mathrm{IC}_{50}\right.$ value) by establishing dose response curves for each cell line (Figure 5A, B). Furthermore, we performed colony formation assay for the measurement of cell contact independent growth. We determined the clonogenic survival fraction by calculating the ratio of cells treated with TKI-258 $(1 \mu \mathrm{M})$ compared to untreated control $(0 \mu \mathrm{M})$ (Figure 6A, B). These data were analyzed by linear regression analyses between the EMT-score (data from Figure 4) and the $\mathrm{IC}_{50}$ value (data from Figure $5 \mathrm{~B}$ ) and between the EMT-score and the clonogenic survival fraction (data from Figure 6B). We observed significant correlations between EMT-score and $\mathrm{IC}_{50}$ values (Figure 7A) and between EMT-score and clonogenic survival fractions (Figure 7B).

In conclusion, the EMT status as determined by Ecadherin and $\mathrm{N}$-cadherin mRNA levels demonstrated significant correlation with cellular TKI-258 responses as studied by different experimental approaches in bladder cancer cell lines. 


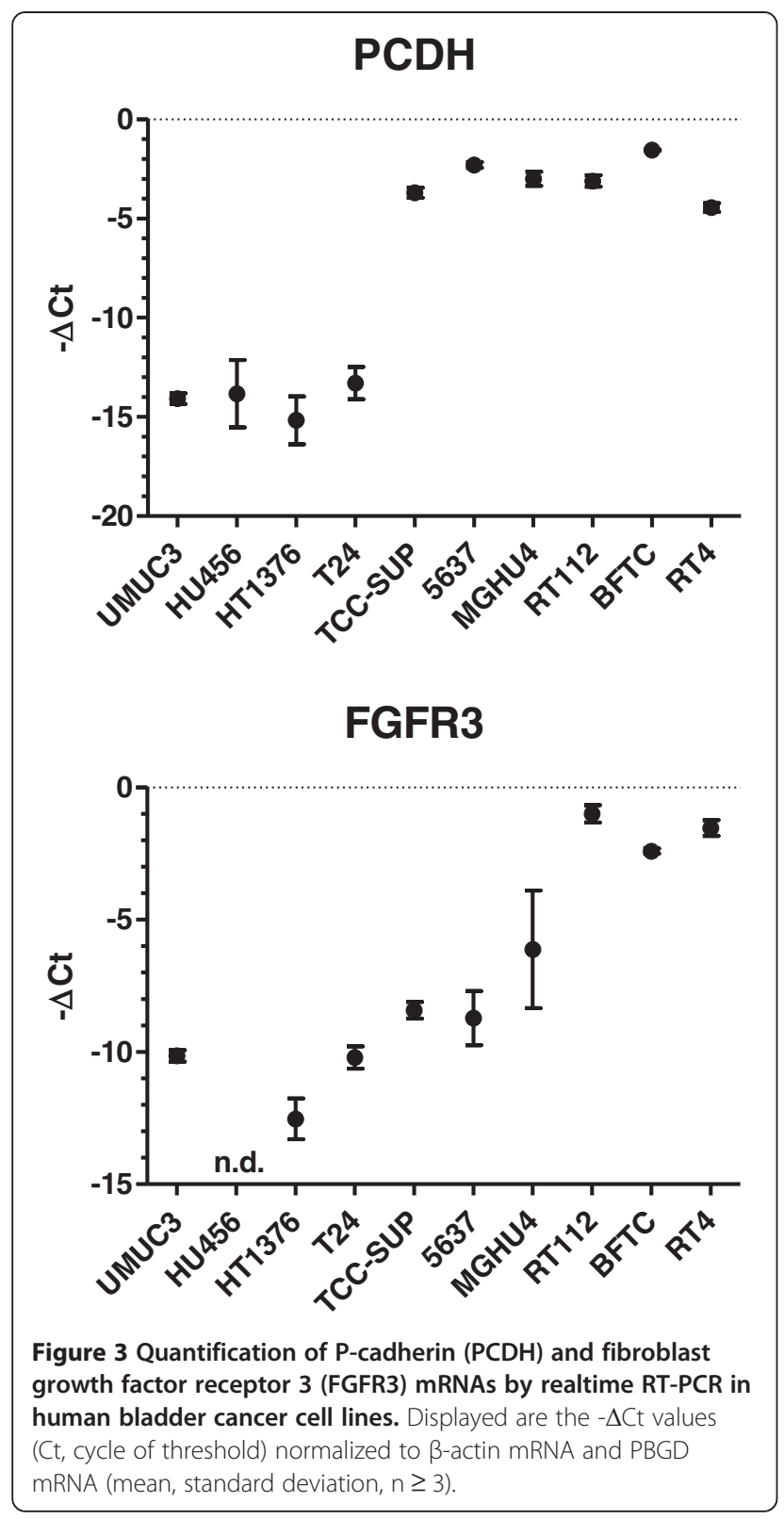

\section{Discussion}

The EMT status reflects features of cancer cells that favor cell migration and invasion, characteristics that are linked to metastasis. Epithelial-like cells are crucially characterized by E-cadherin and mesenchymal-like cells by $\mathrm{N}$ cadherin expression. In cancer, the EMT status reflects the issue of complex cell signaling mechanisms including RTK pathways [24]. Aberrant signaling of RTKs has been described in bladder cancer [25]. Therefore, TKIs are studied for therapy of bladder cancer however, the therapeutic responses vary and are difficult to predict.

Here, we investigated the EMT status in bladder cancer cell lines and tested whether the EMT status is associated with therapeutic responses towards TKI-258. Most importantly,

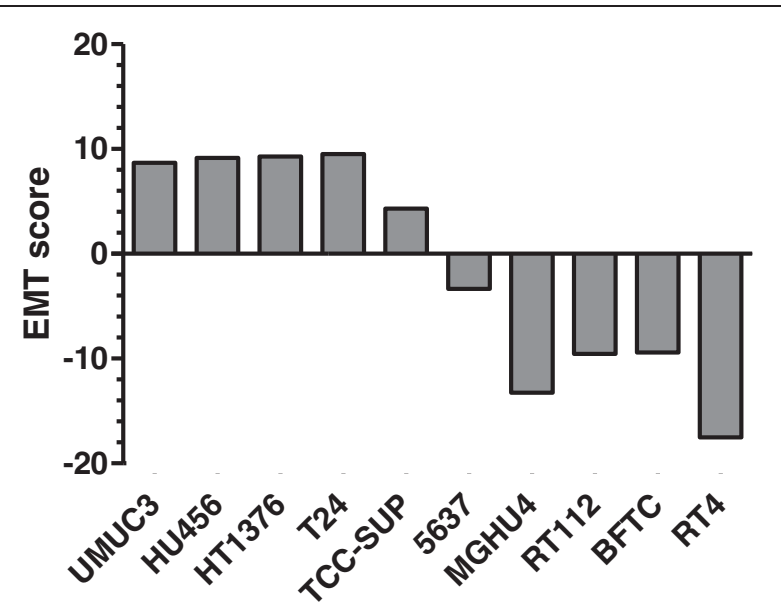

Figure 4 Calculation of an EMT-score for each bladder cancer cell line by subtraction of $-\Delta \mathrm{ct}[\mathrm{NCDH}]--\Delta \mathrm{ct}[\mathrm{ECDH}]$ (data from Figure 2). This score allows quantitative evaluation of mesenchymal (high values) and epithelial (low values) characteristics.

we demonstrated: 1) E-cadherin and N-cadherin protein levels were expressed complementary and correlated with their respective mRNA levels. 2) N-cadherin and E-cadherin mRNA levels served for calculation of an EMT-score indicating the EMT status. High values reflected a relative mesenchymal cell type and low values an epithelial-like cell type. 3) Analysis of the EMT-score and cell responses towards TKI-258 treatment revealed correlations that indicated epithelial-like cells as more therapeutically responsive than mesenchymal-like cells.

Beside the well defined role of E-cadherin and $\mathrm{N}$ cadherin in EMT, we also included P-cadherin in our studies. We observed striking correlation of P-cadherin and E-cadherin mRNA levels supporting a possible association of P-cadherin with epithelial characteristics. This finding is in line with studies where P-cadherin was observed to be enhanced in low grade non muscle invasive bladder cancer indicating epithelial differentiation [16,26]. Other studies revealed correlation of P-cadherin levels with increasing tumor and grading stage indicating a mesenchymal characteristic $[14,27,28]$. In contrast, the role of $\mathrm{N}$-cadherin and E-cadherin in EMT is clearly defined. Therefore, calculation of an EMT-score based on these cadherin subtypes appeared reasonably and revealed correlations with TKI258 responses in all cell assays performed.

Noteworthy, RTK signaling is related to the expression of epithelial and mesenchymal markers. In particular, FGFR3 mRNA correlated with E-cadherin mRNA [7] as confirmed in the cell lines in our study. Furthermore, FGFR1 mRNA expression (not investigated in our study) correlated with the mesenchymal marker $\mathrm{N}$ cadherin [7]. Thus, the analysis of the EMT may be an alternate clue to predict responses towards inhibition of RTK signaling in cancer cells without the need to 

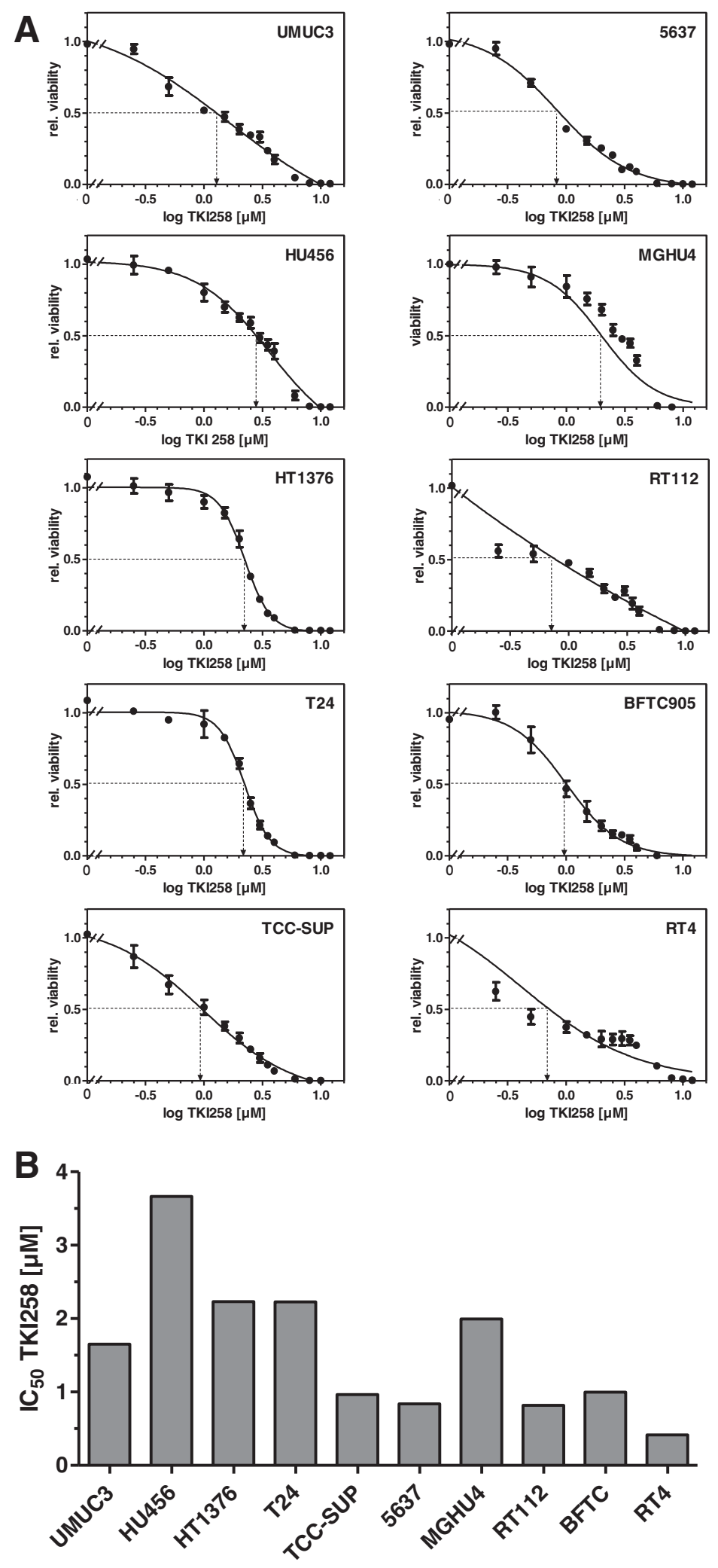

Figure 5 Calculation of IC50 values for TKI-258 treatment. A) Proliferation/viability XTT assay in human bladder cancer cell lines. The IC50 values were determined by curve fitting with non-linear regression analysis (sigmoidal dose response). B) The IC50 values for each cell line are summarized. 


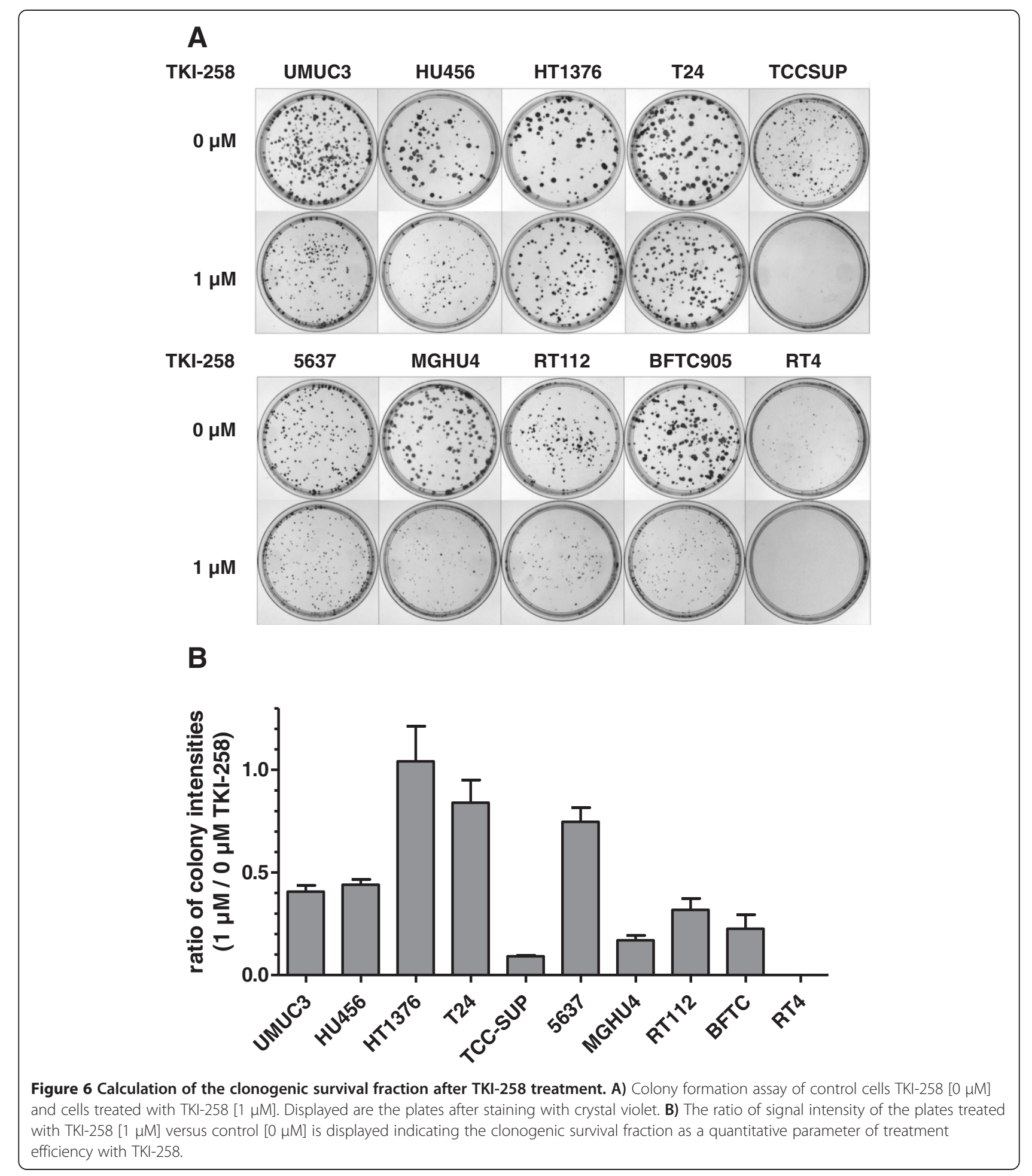

identify possible aberrations of RTK or downstream components by molecular diagnostics. Noteworthy, prediction of cellular responses towards TKI-258 solely based on mutation studies of FGFR have failed and the identification of superior biomarkers is desirable [10]. The analysis of EMT parameters as performed in our study in human cancer cell lines would be also applicable for tumor tissue samples.

Restrictively, it has to be addressed that TKI-258 targets several RTKs namely those of the ligands VEGF, PDGF and FGF that represent growth and angiogenic factors [1,29]. Thus, in vivo effects of TKI-258 are certainly more complex 


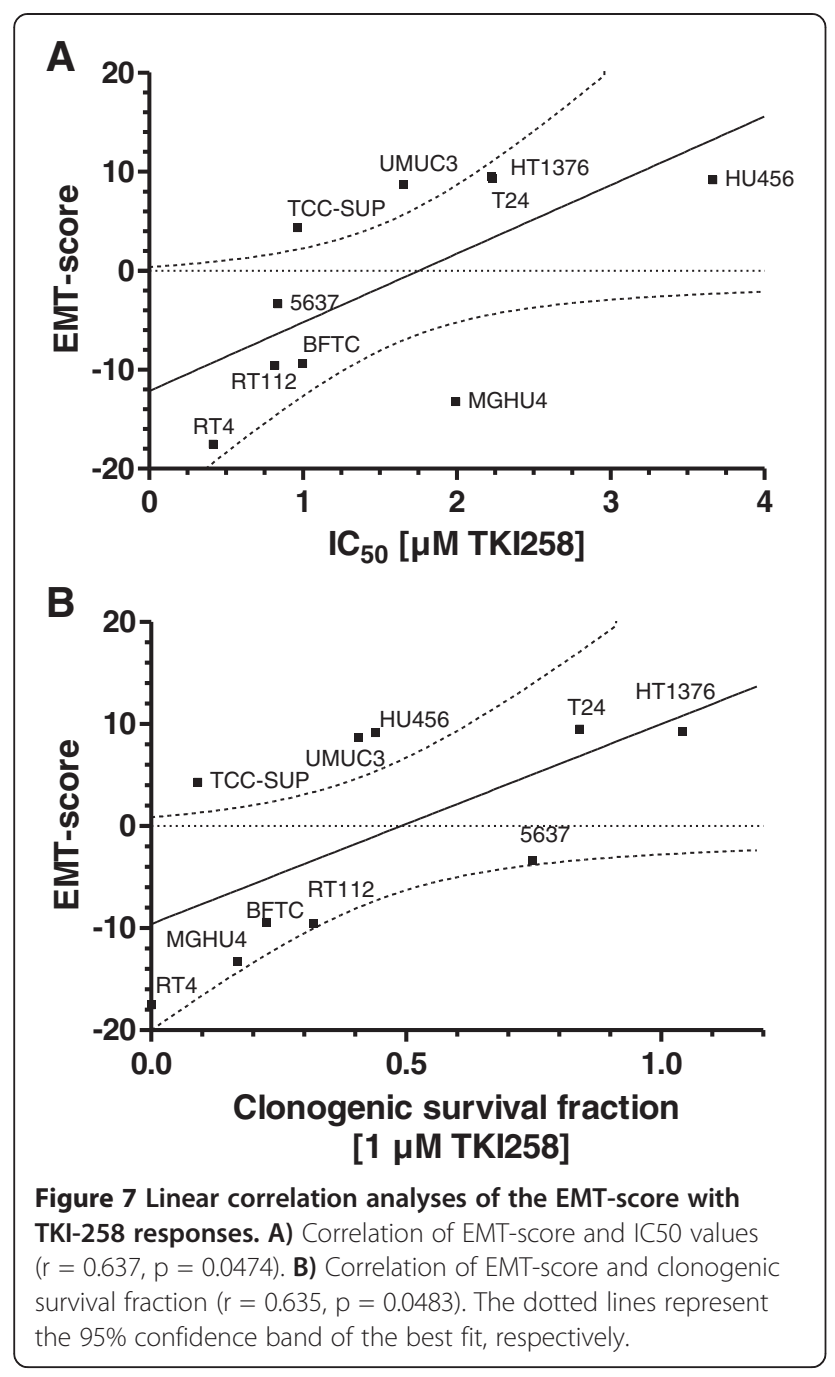

and comprise effects on tumor angiogenesis. Moreover, effects of TKI-258 have not only been attributed to inhibition of RTKs. Namely, topoisomerase II has been demonstrated as target of TKI-258 causing cytotoxic DNA double strand breaks [30].

\section{Conclusions}

Aberrant cellular processes that contribute to bladder tumorigenesis comprise altered signaling of RTKs. Thus, tyrosine kinase inhibitors such as TKI-258 are under investigation for the treatment of bladder cancer. Here we demonstrated that the EMT status determined by Ecadherin and $\mathrm{N}$-cadherin expression levels is associated with responses towards TKI-258 treatment. In particular, TKI-258 was more effective in epithelial-like than in mesenchymal-like bladder cancer cells. Therefore, determination of the EMT status may be exploited as putative predictor for treatment responses of TKI-258 in bladder cancer.

\section{Competing interests}

The authors declare that they have no competing interests.

\section{Authors' contributions}

Conception and design: $\mathrm{JH}, \mathrm{MH}, \mathrm{AH}, \mathrm{RH}, \mathrm{PJO}$. Development of methodology: $\mathrm{MH}, \mathrm{JH}$. Acquisition of data: $\mathrm{MH}, \mathrm{JH}$. Analysis and interpretation of data: $\mathrm{JH}$, $\mathrm{MH}$. Writing and reviewing of the manuscript: $\mathrm{JH}, \mathrm{MH}, \mathrm{PJO}$. All authors read and approved the final manuscript.

\section{Acknowledgements}

This work was supported by Novartis Pharma GmbH, Basel, Switzerland. We thank Ecaterina Oplesch for excellent technical assistance.

Received: 28 August 2013 Accepted: 6 December 2013 Published: 11 December 2013

\section{References}

1. Turner N, Grose R: Fibroblast growth factor signalling: from development to cancer. Nat Rev Cancer 2010, 10(2):116-129.

2. Sibley K, Stern $P$, Knowles MA: Frequency of fibroblast growth factor receptor 3 mutations in sporadic tumours. Oncogene 2001, 20(32):4416-4418.

3. Tomlinson DC, Baldo O, Harnden P, Knowles MA: FGFR3 protein expression and its relationship to mutation status and prognostic variables in bladder cancer. J Pathol 2007, 213(1):91-98.

4. Tomlinson DC, Hurst CD, Knowles MA: Knockdown by shRNA identifies S249C mutant FGFR3 as a potential therapeutic target in bladder cancer. Oncogene 2007, 26(40):5889-5899.

5. Diez de Medina SG, Chopin D, el Marjou A, Delouvee A, LaRochelle WJ, Hoznek A, Abbou C, Aaronson SA, Thiery JP, Radvanyi F: Decreased expression of keratinocyte growth factor receptor in a subset of human transitional cell bladder carcinomas. Oncogene 1997, 14(3):323-330.

6. Tomlinson DC, Lamont FR, Shnyder SD, Knowles MA: Fibroblast growth factor receptor 1 promotes proliferation and survival via activation of the mitogen-activated protein kinase pathway in bladder cancer. Cancer Res 2009, 69(11):4613-4620.

7. Cheng T, Roth B, Choi W, Black PC, Dinney C, McConkey DJ: Fibroblast growth factor receptors- 1 and -3 play distinct roles in the regulation of bladder cancer growth and metastasis: implications for therapeutic targeting. PLoS One 2013, 8(2):e57284.

8. Homsi J, Daud Al: Spectrum of activity and mechanism of action of VEGF/PDGF inhibitors. Cancer Control 2007, 14(3):285-294.

9. Folkman J: Angiogenesis: an organizing principle for drug discovery? Nat Rev Drug Discov 2007, 6(4):273-286.

10. Lamont FR, Tomlinson DC, Cooper PA, Shnyder SD, Chester JD, Knowles MA: Small molecule FGF receptor inhibitors block FGFR-dependent urothelial carcinoma growth in vitro and in vivo. Br J Cancer 2011, 104(1):75-82.

11. Lee SH, Lopes de Menezes D, Vora J, Harris A, Ye H, Nordahl L, Garrett E, Samara $\mathrm{E}$, Aukerman $\mathrm{SL}$, Gelb $\mathrm{AB}$, et al: In vivo target modulation and biological activity of CHIR-258, a multitargeted growth factor receptor kinase inhibitor, in colon cancer models. Clin Cancer Res 2005, 11(10):3633-3641.

12. Yao D, Dai C, Peng S: Mechanism of the mesenchymal-epithelial transition and its relationship with metastatic tumor formation. Mol Cancer Res 2011, 9(12):1608-1620.

13. McConkey DJ, Choi W, Marquis L, Martin F, Williams MB, Shah J, Svatek R, Das A, Adam L, Kamat A, et al: Role of epithelial-to-mesenchymal transition (EMT) in drug sensitivity and metastasis in bladder cancer. Cancer Metastasis Rev 2009, 28(3-4):335-344.

14. Bryan RT, Tselepis C: Cadherin switching and bladder cancer. J Urol 2010, 184(2):423-431.

15. Jeanes A, Gottardi CJ, Yap AS: Cadherins and cancer: how does cadherin dysfunction promote tumor progression? Oncogene 2008, 27(55):6920-6929.

16. Jager T, Becker M, Eisenhardt A, Tilki D, Totsch M, Schmid KW, Romics I, Rubben $H$, Ergun $S$, Szarvas $T$ : The prognostic value of cadherin switch in bladder cancer. Oncol Rep 2010, 23(4):1125-1132.

17. Thiery JP, Sleeman JP: Complex networks orchestrate epithelialmesenchymal transitions. Nat Rev Mol Cell Biol 2006, 7(2):131-142.

18. Fuxe J, Vincent T, Garcia de Herreros A: Transcriptional crosstalk between TGF-beta and stem cell pathways in tumor cell invasion: role of EMT promoting Smad complexes. Cell Cycle 2010, 9(12):2363-2374. 
19. Blaveri E, Simko JP, Korkola JE, Brewer JL, Baehner F, Mehta K, Devries S, Koppie T, Pejavar S, Carroll P, et al: Bladder cancer outcome and subtype classification by gene expression. Clin Cancer Res 2005, 11(11):4044-4055.

20. Dinney CP, McConkey DJ, Millikan RE, Wu X, Bar-Eli M, Adam L, Kamat AM Siefker-Radtke AO, Tuziak T, Sabichi AL, et al: Focus on bladder cancer. Cancer Cell 2004, 6(2):111-116.

21. Sanchez-Carbayo M, Socci ND, Lozano J, Saint F, Cordon-Cardo C: Defining molecular profiles of poor outcome in patients with invasive bladder cancer using oligonucleotide microarrays. J Clin Oncol 2006, 24(5):778-789.

22. Black PC, Brown GA, Inamoto T, Shrader M, Arora A, Siefker-Radtke AO, Adam L, Theodorescu D, Wu X, Munsell MF, et al: Sensitivity to epidermal growth factor receptor inhibitor requires E-cadherin expression in urothelial carcinoma cells. Clin Cancer Res 2008, 14(5):1478-1486.

23. Shrader M, Pino MS, Brown G, Black P, Adam L, Bar-Eli M, Dinney CP, McConkey DJ: Molecular correlates of gefitinib responsiveness in human bladder cancer cells. Mol Cancer Ther 2007, 6(1):277-285.

24. Grunert S, Jechlinger $\mathrm{M}$, Beug $\mathrm{H}$ : Diverse cellular and molecular mechanisms contribute to epithelial plasticity and metastasis. Nat Rev Mol Cell Biol 2003, 4(8):657-665.

25. Mitra AP, Cote RJ: Molecular pathogenesis and diagnostics of bladder cancer. Annu Rev Pathol 2009, 4:251-285.

26. Mandeville JA, Silva Neto B, Vanni AJ, Smith GL, Rieger-Christ KM, Zeheb R, Loda M, Libertino JA, Summerhayes IC: P-cadherin as a prognostic indicator and a modulator of migratory behaviour in bladder carcinoma cells. BJU Int 2008, 102(11):1707-1714.

27. Bryan RT, Atherfold PA, Yeo Y, Jones LJ, Harrison RF, Wallace DM, Jankowski JA: Cadherin switching dictates the biology of transitional cell carcinoma of the bladder: ex vivo and in vitro studies. J Pathol 2008, 215(2):184-194.

28. Rieger-Christ KM, Cain JW, Braasch JW, Dugan JM, Silverman ML, Bouyounes B, Libertino JA, Summerhayes IC: Expression of classic cadherins type I in urothelial neoplastic progression. Hum Pathol 2001, 32(1):18-23.

29. Witsch $E$, Sela $M$, Yarden $Y$ : Roles for growth factors in cancer progression. Physiology (Bethesda) 2010, 25(2):85-101.

30. Hasinoff BB, Wu X, Nitiss JL, Kanagasabai R, Yalowich JC: The anticancer multi-kinase inhibitor dovitinib also targets topoisomerase I and topoisomerase II. Biochem Pharmacol 2012, 84(12):1617-1626.

doi:10.1186/1471-2407-13-589

Cite this article as: Hänze et al.: Epithelial mesenchymal transition status is associated with anti-cancer responses towards receptor tyrosinekinase inhibition by dovitinib in human bladder cancer cells. BMC Cancer 2013 13:589.

\section{Submit your next manuscript to BioMed Central and take full advantage of:}

- Convenient online submission

- Thorough peer review

- No space constraints or color figure charges

- Immediate publication on acceptance

- Inclusion in PubMed, CAS, Scopus and Google Scholar

- Research which is freely available for redistribution 